\title{
Resilience: Paradoxical insight or conceptual poverty?
}

Colin R. Martin

Faculty of Society and Health, Buckinghamshire New University, Uxbridge, Middlesex, UK

Address for correspondence:

Professor Colin R Martin

Room 2.11

Faculty of Society and Health

Buckinghamshire New University

Uxbridge Campus

106 Oxford Road, Uxbridge, Middlesex, UB8 1NA, UK.

Tel: 01494522141 Extension 2349

Fax: $01494603179 \quad$ Email: colin.martin@bucks.ac.uk 


\begin{abstract}
Purpose: This paper looks at some of the evidence that supports the construct of resilience and the operationalisation of the 'phenomena' of resilience within contemporary society. The concept of resilience has become an influential and society-wide construct, embraced by the positive psychology movement and impacting on educational, health and social policy significantly and demonstrably. Importantly, the concept of resilience has a substantial historical heritage and legacy and the permeation of the construct within the collective social consciousness is rarely considered or queried, but generally accepted and embraced. Moreover, the construct of resilience within itself is invariably couched within contemporary discourse as a universal good and highly desirable attribute and further still, considered by many as a fundamental component contributing to the fabric of an individuals' character.
\end{abstract}

Approach: A short review of selective evidence of key conceptual issues.

Findings: Resilience as a concept, is defuse, generally ill-defined and highly subjective. The concept of resilience, though popular and intrinsic to a number of aspects of public and educational policy remains controversial, provides an explanatory account of differential outcomes which may not always be positive and importantly, may potentially disenfranchise the individual.

Originality: The synthesis of the brief and selective appraisal of evidence in this area suggests that the concept of resilience, if it exists at all, is highly mercurial, ambiguous in definition and despite its omnipresence as a representation of a positive and internalised attribution to the individual, has a significant negative side which is seldom considered. Querying the concept of resilience against the overwhelming backdrop of positive belief and opinion regarding the concept may represent a social heresy, however, the balance of evidence would suggest a debate about the concept is long overdue and moreover, the concept itself provides a useful fulcrum to consider where beliefs, attitudes and opinions about abstract concepts stop and science, evidence and fact-based reflection begin.

Key words: Education, Mental Health, Resilience, Well-being 


\section{Introduction}

The recent tragedy of the German Wings airliner crash offers a societal-wide mirror with which to consider some of the profoundly meaningful emotions that epitomise the condition human, such as grief, anger and sorrow. Moreover, these thankfully rare events also allow consideration of other concepts, benign and malevolent, and all the shades in between, which permeate our collective social construction over time, slowly, inexorably and insidiously, akin to a 'group think' phenomena, the irresistible power of novel conceptual mileu, fashioned and incorporated into the fabric of society, anoetically and without awareness, the most powerful example of a social-cultural osmosis. How then, does this relate to the tragic events of a young pilot committing suicide and concomitantly committing mass murder? A common pathway linking victim and perpetrator in this instance may be the concept of resilience. Resilience describes the attributes an individual displays often within the context of adversity, the concept itself often being synonymous with the notion of desirable character attributes. The powerful example of the aircrash allows one to ponder the duality of the concept of resilience, on the one hand, the grief-stricken families with relatively high levels of resilience may be anticipated to cope with their loss and accompanying distress more effectively thank those lower on the resilience attributional quotient. Put simply, those with greater levels of resilience may be anticipated to cope better, comparatively, be less prone to anxiety, depression, somatisation or even more exotic forms of mental health concerns such psychosis. Those with greater resilience will be on the road to a speedier and more effective adaptation to loss and ultimately reconcile better, the feelings of loss, distress and abandonment of the loved one. What then the pilot? Given the gravity of the crime it is both uncomfortable and disconcerting the consider the perpetrator of the crime may share, even in part, some form of similarity, kinship, identity or commonality with the relatives, siblings, mothers, fathers and children of the dead. However, the reality is, within the evidence arch which purports to support the legitimacy of the resilience concept, the pilot shares the same resilience qualities. How can this be? Considering some of the known facts of the case, it would seem that the pilot himself had experienced some mental health challenges prior to qualifying as an airliner pilot, yet despite the burden of considerable mental health distress, the pilot diligently completed his flight training, qualified as a pilot and joined an airline. Therefore the 
explanatory conduit between pilot training and prior psychological distress is the conduit of resilience. The absolute and all-consuming grief accompanying such a profoundly awful event as an adaptation process contrasting markedly with the pilot completing his training against a background of mental health lability share a common conceptual pathway to the society engendered concept we now describe as resilience.

The above proposition raises a number of profound questions, most notably and dispassionately about a common conceptual pathway representative of good and evil and indeed, perhaps from a Nietzcherian perspective, beyond good and evil. The seeming confusion among the actual conceptualisation of what resilience represents is likely to relate to its penetration into contemporary culture as a 'buzz word', thus individuals have a sense of what it is and a mental model but of course, during a discourse between two or more people about resilience, each person may have a different construct of the term. Beyond the purely academic consideration of the concept of resilience is the real and established translation of this mercurial notion into educational and social policy, for example, for at least a decade the adoption of approaches and interventions within schools to promote resilience among children.

There are many definitions of resilience and a personally favoured useful one is that of Atkinson, Martin and Rankin (2009) which describes resilience as 'The ability to apparently recover from the extremes of trauma, deprivation, threat or stress is known as resilience' (Atkinson et al., 2009, p.137). This definition is useful as it highlights the dynamic nature of the concept, essentially the necessity for a significant cue, for example a threat, to 'activate' the concept. One striking observation is that generally, resilience is perceived as a very positive attribute. However, as the aviation example above demonstrates, the concept also has a negative aspect, and certainly, within the course of this paper, it is conjectured that the negative aspects of resilience may be as equal in magnitude as the good.

Resilience is endorsed conceptually by the positive psychology movement and considered an essential pre-requisite for personal emotional and psychological growth and general well-being. This position is clearly at odds with Atkinson et al.'s (2009) definition which requires the concept to be operationalised through reaction to 
an adversive stimulus. This small example gives a clear indication of how confusion may arise in the appraisal of the resilience concept, however the root of such confusion lies in an historical legacy going back over a century. The classic example is the legendary rescue of his ship-wrecked men from Elephant Island accomplished by Ernest Shackleton. Not only did this event meld with the desirable traits of courage and bravery at the fundamental level of the individual's character, but this specific example has become an enduring staple of resilience in the face of extreme adversity. Described in detail in our paper (Atkinson et al., 2009), the permanence of this particular event in the literature on resilience, the importance of it being of such a magnitude that it is still used within the developmental framework of instruments developed to measure the concept, for example Connor and Davidson (2003). It should however be considered that, and in no way diminishing Shackleton's incredible achievement, that the reality was that his small boat undertaking a dramatic sea voyage in order to obtain help for his marooned men could have been easily overtaken by a severe storm and lost without trace. Thus, it must be reflected upon that to a degree Shackleton's success must incorporate a component of serendipity. Accepting this, then we must also acknowledge a potential fallacy in ascribing the development of a model of resilience informed in part by serendipity and the implications there of. Therefore, by doing so we enter the realm of beliefs and ideologies and close the door on the world of science and empiricism. It is opportune then to consider other historical accounts which may be less noteworthy in terms of not being identified with a specific figure, but nonetheless give unique insight into motivational factors which influence the construct of resilience. Atkinson et al. (2009) discuss the experience of Jewish nurses in the Auschwitz-Birkenau concentration camp whose resilience was largely a function of their desire to care for others summarising key detail of the documentation of Brush (2004) and contrast this with other groups of nurses in Germany during the second world war who enthusiastically embraced murdering patients in their care as part of the 'Euthanasia' programmes for individuals with physical disability or mental health concerns. It could therefore be conjectured that both groups of nurses as described, demonstrate resilience, however, the manifestation of such resilience represent diametric opposites in terms of compassion, empathy, respect for others, dignity and wellbeing. 
What then, does all of this mean when we consider some of the examples above within our everyday work environment or indeed out home and social environment? Consider the teacher supporting a learner who is being bullied and seems to be coping well, is he or she any more resilient than another learner in the same context but who reveals a higher degree of emotional reaction and distress? If we were to consider that the first learner is more resilient, what does that potentially mean in terms of our attributions about the students character, their ability to cope and their social skills set? The introduction of the concept of resilience as an explanatory account in this context may be little more than representative of a cognitive distortion on the part of the teacher, however, this cognitive distortion is critically important as of course it will influence behaviour, including engagement with the learner. This represents an insidious aspect of resilience, we may activate the cognitive schemata that propagates attributional scripts regarding the individual concerned, but we may not be aware of how these attributional scripts will affect our own behaviour toward the learner. Doll and Lyon (1998) have described the resilience movement rather elegantly as faddism, thus disembodying the concept from a legitimate and coherent evidence base. A critical issue is that resilience presents solutions and explanations to complex and often difficult phenomena. Given the current economic situation and the starvation of resources within education and health in particular, the appeal of the concept of resilience is likely to develop further prominence and penetration, despite the lack of a coherent evidence base to support that the notion exists. Throwing this point into sharp relief is that the poverty of the evidence base is framed within the context of one of the most enduring 'concepts' of relevance to applied psychology. The application of the concept to real-life situations within an explanatory account raises a number of fundamental concerns. There are many instances where the acceptance of the resilience concept can lead to extremely negative attributions, for example the cancer patient who 'loses their fight' with cancer because they were not resilient enough to 'fight it', the attribution being here that if they were resilient enough they would beat the disease. Another example is the abstinent 'alcoholic' who remains sober because they have been told they have an 'allergy' to alcohol. Interestingly, in this instance the attribution of sobriety is assumed to be the resilience of the individual when in actual fact, it's the individual 'buying in' to a non-evidence based belief system, the 'allergy' to alcohol. A final example might be the teenage learner who develops an eating disorder and an 
attribution of 'lack of resilience' is made when there are several, plausible and realistic alternative explanations that may be precipitating the eating disorder. In all cases, the application of the resilience concept serves only to disenfranchise the individual concerns, stagnate the individual within their current negative circumstances and paradoxically foster a sense of an external locus of control, an external locus of control generally being associated with comparatively deleterious outcomes (Martin, 1999).

Beginning this discourse on the nature and challenges of the resilience concept, the pervasiveness central to its longevity is often linked to it being intertwined with the character of an individual. Heroic historical figures are often used as a cause celeb to support this notion and on the surface the illusory correlation that is drawn between the actors actions and their character can be irresistibly convincing. However, it is incumbent on all of us, especially those of us with a duty of care to others, irrespective of whether that be within the education, health or social care setting, to consider carefully the translation of behavioural instances associated with specific, often one-off, events, to be a defining feature of an individual's character in terms of a trait, as opposed to a state, of resilience. Reflecting on the definition of resilience proposed by Atkinson et al. (2009) which specifically emphasises, by definitional implication, that for resilience to exist it can only exist in a state of reactivity, it is reassuring to find support for this perspective from influential researcher in the field, including Michael Rutter (2007). However, there exists a strand of research actively seeking to establish that there is evidence that resilience represents a personality trait (for example, Waugh et al., 2008) and the two camps within this academic, translationally relevant debate, represent ideological positions which are unlikely to reconciled in the short-term.

\section{Conclusion}

In summary, the above discourse represents the 'laying out of stall' on some of the issues and challenges that are implicit to the seemingly innocuous term 'resilience'. There is much more to be said and for those readers interested in this debate the paper of Atkinson et al. (2009) provides a useful, for the most part balanced, and entirely evidence-based review of the contemporary issues associated with the 
concept, as does our later paper which has more of a psychiatric application and focus (Atkinson et al., 2010). This paper was written in the spirit of raising awareness of some of the issues and presenting a context for reflection and consideration. Against a contemporary background that generally perceives the concept of resilience as an almost universal good, the opportunity to consider carefully and proportionately such a suggestion is valuable, not only in introducing balance into the debate, but also in terms of the translation of our own thoughts, insights and beliefs about the concept within our own workplaces and indeed social mileu and the potential impact circumscribed by our own attitudes to the concept. Paradoxical insight or conceptual poverty, either way, the concept of resilience permeates the fabric and social construction of all our lives. 


\section{References}

Atkinson, P.A., Martin, C.R. and Rankin, J. (2009) Resilience Revisited. Journal of Psychiatric and Mental Health Nursing 16, 137-145.

Atkinson, P.A., Atkinson, J.M., Martin, C.R. and Rankin, J. (2010) Historical perspectives on resilience and concepts of relevance for mental health. RSF: Rivista Sperimentale di Freniatria 84, 21-40.

Brush B.L. (2004) Nursing care and context in Theresienstadt. Western Journal of Nursing Research 26, 860-871.

Connor K. \& Davidson J. (2003) Development of a new resilience scale: the Connor Davidson Resilience Scale (CD-RISC). Depression and Anxiety 18, 76-82.

Doll B. \& Lyon M.A. (1998) Risk and resilience: implications for the delivery of educational and mental health services in schools. School Psychology Review 27, 348-363.

Martin, C.R. (1999) Phasic influences on psychometric measures during the menstrual cycle: Implications for the construct integrity of the locus of control dimension. British Journal of Medical Psychology 72, 217-226.

Rutter M. (2007) Resilience, competence and coping. Child Abuse and Neglect 31, 205-209.

Waugh C.E., Fredrickson B.L. \& Taylor S.F. (2008) Adapting to life's slings and arrows: individual differences in resilience when recovering from an anticipated threat. Journal of Research in Personality 42, 1031-1046. 